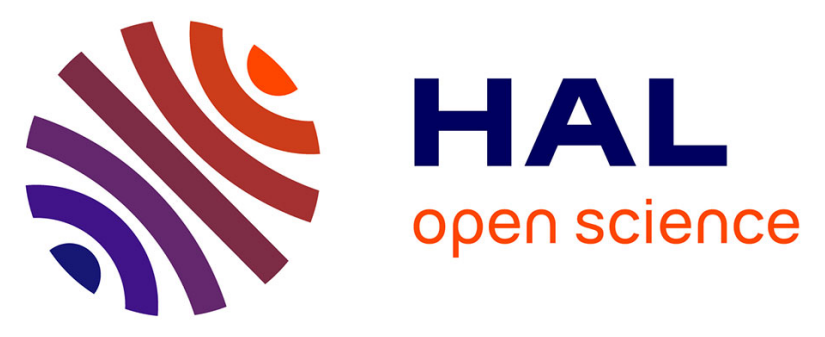

\title{
Influence of growth modulation on the effective permeability of the vertebral end plate. A porcine experimental scoliosis model
}

Franck Accadbled, Jean-Michel Laffosse, Thierry Odent, Anne

Gomez-Brouchet, Jérôme Sales de Gauzy, Pascal Swider

\section{To cite this version:}

Franck Accadbled, Jean-Michel Laffosse, Thierry Odent, Anne Gomez-Brouchet, Jérôme Sales de Gauzy, et al.. Influence of growth modulation on the effective permeability of the vertebral end plate. A porcine experimental scoliosis model. Clinical Biomechanics, 2011, 26 (4), pp.337-342. 10.1016/j.clinbiomech.2010.11.007 . hal-01590827

\section{HAL Id: hal-01590827 \\ https://hal.science/hal-01590827}

Submitted on 20 Sep 2017

HAL is a multi-disciplinary open access archive for the deposit and dissemination of scientific research documents, whether they are published or not. The documents may come from teaching and research institutions in France or abroad, or from public or private research centers.
L'archive ouverte pluridisciplinaire $\mathbf{H A L}$, est destinée au dépôt et à la diffusion de documents scientifiques de niveau recherche, publiés ou non, émanant des établissements d'enseignement et de recherche français ou étrangers, des laboratoires publics ou privés. 


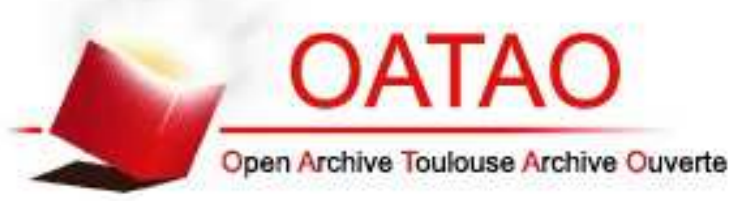

\section{Open Archive TOULOUSE Archive Ouverte (OATAO)}

OATAO is an open access repository that collects the work of Toulouse researchers and makes it freely available over the web where possible.

This is an author-deposited version published in : http://oatao.univ-toulouse.fr/ Eprints ID : 18180

To link to this article : DOI: $10.1016 /$ j.clinbiomech.2010.11.007 URL : http://dx.doi.org/10.1016/j.clinbiomech.2010.11.007

To cite this version : Accadbled, Franck and Laffosse, Jean-Michel and Odent, Thierry and Gomez-Brouchet, Anne and Sales de Gauzy, Jérôme and Swider, Pascal Influence of growth modulation on the effective permeability of the vertebral end plate. A porcine experimental scoliosis model. (2011) Clinical Biomechanics, vol. 26 $\left(\mathrm{n}^{\circ} 4\right)$. pp. 337-342. ISSN 0268-0033

Any correspondence concerning this service should be sent to the repository administrator: staff-oatao@ listes-diff.inp-toulouse.fr 


\title{
Influence of growth modulation on the effective permeability of the vertebral end plate. A porcine experimental scoliosis model
}

\author{
Franck Accadbled a,b,*, Jean-Michel Laffosse ${ }^{\mathrm{b}, \mathrm{c}}$, Thierry Odent ${ }^{\mathrm{d}, \mathrm{e}}$, Anne Gomez-Brouchet ${ }^{\mathrm{f}}$, \\ Jérôme Sales de Gauzy ${ }^{\mathrm{a}, \mathrm{b}}$, Pascal Swider ${ }^{\mathrm{b}}$ \\ a Department of Paediatric Orthopaedic Surgery, Children Hospital, Toulouse University Hospital, France \\ ${ }^{\mathrm{b}}$ IMFT UMR CNRS 5502, University of Toulouse, France \\ c Department of Orthopaedic Surgery, Rangueil Toulouse University Hospital, France \\ d Department of Paediatric Orthopaedic Surgery, Necker Children Hospital, Paris V University Hospital, France \\ e Department of Surgery, National Veterinary School of Lyon, France \\ ${ }^{\mathrm{f}}$ Department of Pathology, Rangueil Toulouse University Hospital, France
}

Keywords:

Spine

Scoliosis

Permeability

Intervertebral disc

Vertebral end plate

Animal disease model

\begin{abstract}
A B S T R A C T
Background: Abnormal mechanical loading occurs in scoliosis as compared to normal spines. Intervertebral disc degeneration has been correlated with alteration of bone density in adjacent vertebral bodies. How vertebral end plate remodels in scoliosis and the consequences on disc homeostasis are not well understood. Permeability is a relevant physical measure to quantify mass transport in porous media. We hypothesized that effective permeability of the vertebral end plate was modified by growth modulation in a scoliosis animal model.

Methods: Flexible asymmetric posterior instrumentation was undertaken on six healthy four-week-old pigs. Two sets of left pedicle screws were inserted and connected with a stainless steel cable. After two months, the apical intervertebral unit and three units located cranially and caudally, were harvested. One central and two lateral specimens were investigated using a previously validated method for measuring permeability.

Findings: A three-dimensional deformity was obtained in all six animals with an average of $42^{\circ}$ right thoracic curve, $44^{\circ}$ lordosis and $21^{\circ}$ rotation. Permeability was significantly greater in the center of the end plates than in the periphery and it was decreased by $-45 \%$ towards the apex of the deformity. Fluid flow direction did not play a significant role. No significant difference was found between the convex side and the concave side.

Interpretation: The end plate is a crucial zone for diffusive and convective transport and we showed in a scoliosis animal model that a growth modulation may decrease its effective permeability. The proposed methodology and associated results could help to understand degenerative changes in human spine.
\end{abstract}

\section{Introduction}

Fusionless surgical techniques have recently been developed to limit deformity progression though allowing spinal growth and mobility in scoliosis infants. They rely on the Hueter Volkmann principle that is a mechanical tether placed in the convexity of a curve thereby alters spinal growth thus gradually corrects the deformity. Various authors have experimented with spinal growth modulation either to correct spinal deformities (Betz et al., 2003) or to create deformities in animal models (Braun et al., 2003, 2006; Newton et al., 2002, 2008a, 2008b; Odent et al., 2008). However, few studies have investigated the resulting condition of the intervertebral disc (IVD) and vertebral end plate (VEP).

Asymmetric loading has a significant influence at the level of the VEP-IVD interface (Braun et al., 2003; Newton et al., 2002; Taylor

\footnotetext{
* Corresponding author. Service de Chirurgie Orthopédique et Traumatologique, Hôpital des Enfants 330, avenue de Grande Bretagne, 31059 Toulouse Cedex 9, France. E-mail address: faccadbled@wanadoo.fr (F. Accadbled).
}

et al., 1976) with remodeling of the VEP and calcifications of the cartilage end plate (CEP). It results in decreased permeability, alteration in IVD cellular function and metabolism and eventually disc degeneration (Nachemson et al., 1970; Roberts et al., 1993, 1996; Urban et al., 2001a, 2001b). Solute exchanges to and from the IVD occur through the VEP both via passive diffusion and active convection (Brodin, 1955; Roberts et al., 1989; Selard et al., 2003). This nutrition route is precarious (Selard et al., 2003; Urban et al., 2001a, 2001b) and compromised in case of VEP degeneration (Accadbled et al., 2008a, 2008b; Donisch and Trapp, 1971) and in scoliosis (Urban et al., 2001a, 2001b).

Permeability is a relevant physical measure to investigate convective and diffusive transport in porous media (Biot, 1941; Dullien, 1992). At Darcy scale and under low flow rates, permeability is independent from boundary conditions, load and pressure conditions which could modify porosity and tortuosity of pore interconnections (Accadbled et al., 2008a).

In this framework, we hypothesized that effective permeability of the vertebral end plate was modified by growth modulation in a 
scoliosis model. Our study aimed at quantifying the changes in the apical zone of the curve in a porcine model obtained by asymmetric posterior spine instrumentation. A microscopic study completed the approach.

\section{Methods}

\subsection{Surgical procedure and specimen preparation}

Asymmetric posterior spine instrumentation was undertaken under general anesthesia on six healthy four week old pigs. Two sets of left pedicle screws ( $\varnothing 4 \mathrm{~mm}$, length $30 \mathrm{~mm}$, Vertex ${ }^{\mathrm{TM}}$ multiaxial screws titanium, Medtronic ${ }$ Sofamor Danek, Memphis, TN, USA) were inserted at levels $T_{5}-T_{6}$ and $L_{1}-L_{2}$ (T: thoracic vertebra, $L$ : lumbar vertebra) through two distinct approaches along with a short rod and lateral connectors. A stainless steel cable (Ø $2 \mathrm{~mm}, 2.4 \mathrm{kN}$ rupture) was then placed in a subcutaneous fashion to connect the thoracic and lumbar constructs without initial tension (Fig. 1) (Odent et al., 2008).

The animals were then observed without further treatment for two months with radiographs at four week intervals. Low molecular weight heparin (4500 IU/ml Innohep ${ }^{\circledR}$ Tinzaparin, Leo Pharma Inc.) was administered once a day for two days before the animals were killed to prevent blood clot formation without any side effect on VEP structure and porosity. Thoracolumbar spine was harvested en bloc and stored into normal saline added with heparin $(100 \mathrm{IU} / \mathrm{ml})$ to prevent tissue dehydration and blood clots. Final coronal and sagittal spine deformity was analyzed on CT scan with Cobb angle which is a measurement used for evaluation of curves in scoliosis on an AP radiographic projection of the spine. A 3D reconstruction of the entire spine was generated by combining a stereoradiographic technique and a geometric and statistic analysis. This technique uses the axial CT scan slices to generate a calibrated 3D image of the spine (Pomero et al. 2004). This allowed locations and orientations of vertebrae to be quantified automatically. Rotation of the apical vertebra was measured in relation with $L_{5}$. The apical intervertebral unit was identified and labeled as $A$, those three units located cranially as $A+1, A+2$, and $A+3$ and those three located caudally as $A-1, A-2$, and $A-3$.

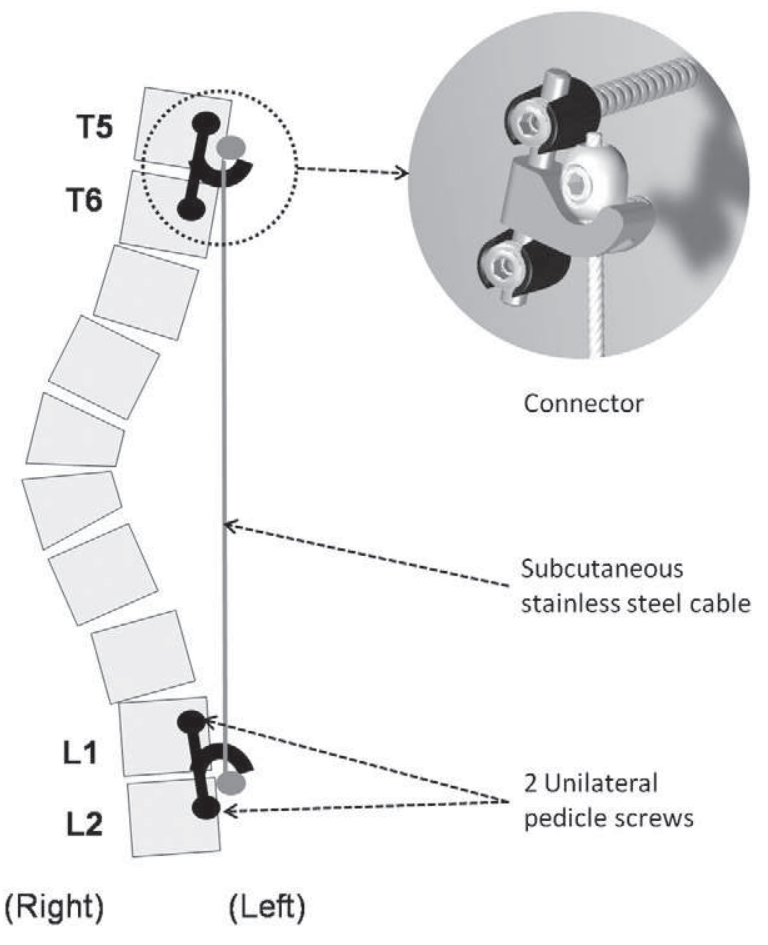

Fig. 1. Asymmetric instrumentation with detail of the lateral cable connector.
VEPs were separated using a powered saw blade. IVD was removed from each plate using a beaver blade under a binocular microscope. Great care was taken to avoid any injury to the CEP. Then, three cylindrical specimens of $5 \mathrm{~mm}$ diameter and $6 \mathrm{~mm}$ length were harvested from each VEP using a custom-made stainless steel cylindrical punch. Each specimen comprised four layers: CEP, epiphysis, growth plate and adjacent trabecular bone. One specimen was taken from the central zone and two were taken laterally, right and left. The specimens were carefully inserted into silicone tubes and then frozen for storage within $6 \mathrm{~h}$ at $-23^{\circ} \mathrm{C}$ in Ringer's solution added with $10 \%$ cryoprotectant dimethyl sulfoxide (DMSO) and $100 \mathrm{IU} / \mathrm{ml}$ heparin (Accadbled et al., 2008b). All experiments were carried out in accordance with the animal welfare regulations and guidelines.

\subsection{Testing apparatus and protocol}

A previously validated method for measuring permeability based on the relaxation pressure due to a transient-flow rate, was used (Accadbled et al., 2008a). The specimens were placed in the testing apparatus and a pistoning device generated a fluid flow that saturated the cylindrical specimen with a maximal pressure of 0.1 to $0.2 \mathrm{MPa}$. The decrease of upstream pressure $P(t)$ was measured using a pressure transducer (TME $®, 0-5$ bars) and Labview ${ }^{\circledR}$ software (National Instrument), which allowed the effective permeability $\kappa / \mu$ of specimens to be derived using Eq. (1) (Accadbled et al., 2008a). Parameters $P_{0}, \mu, \beta, t$, were the initial pressure, the fluid viscosity, the calibrated coefficient of the fixture and the time variable, respectively.

$P(t)=P_{0} e^{(-\kappa t / \mu \beta)}$

The identification of eventual fluid leaks and bulk compressibility modulus was achieved using a semi-rigid non-porous silicon plug (CAF33 Rhône Poulenc®). High bulk compressibility of $3.61 \mathrm{~mm} / \mathrm{MPa}$ (SD 0.18) and negligible leak coefficients of $3096 \times 10^{-4} \mathrm{~mm}^{3} / \mathrm{MPa} \mathrm{s}$ (SD 154) were obtained. The reliability of the measurement process was evaluated using a cylindrically tooled porous hydroxyapatite block from Interpore ${ }^{\circledR}$ (Pro Osteon HA500) with a relative permeability $\kappa \mathrm{S} / \mu$ (intrinsic permeability/ fluid viscosity) of $2.9 \times 10^{-7} \mathrm{~m}^{4} / \mathrm{N} \mathrm{s}$ (SD 0.14 ).

Three measurements were achieved for each specimen and fluid direction (flow in and flow out of the IVD). The three values were then averaged for each flow direction. Each specimen was then fixed in formalin and stored for later microscopic study.

\subsection{Microscopic study}

Thickness of each of the following layers (CEP, epiphysis and growth plate) was measured on six spots between $A-3$ and $A+3$ levels and averaged. Specimens were fixed in $10 \%$ formalin, embedded in paraffin and stained with hematoxylin and eosin. As shown in Fig. 2, specimens were first cut longitudinally to obtain two symmetrical hemicylinders. A histological section was taken from each hemicylinder and two measurements of the thickness of the various layers were made using a microscope and a digital camera on each section. For each layer, the average of the four values obtained was used for analysis.

\subsection{Statistical analysis}

The normality of distributions was verified using the KolmogorovSmirnov test. Variance analysis (ANOVA) was done when the normality of the value was verified. Otherwise, a non parametric test (Kruskal-Wallis) was done followed with a post-hoc analysis. Correlations between effective permeability and microscopic results were sought using Pearson test and with Spearman test when normality was not confirmed. Statistical significance was defined as 


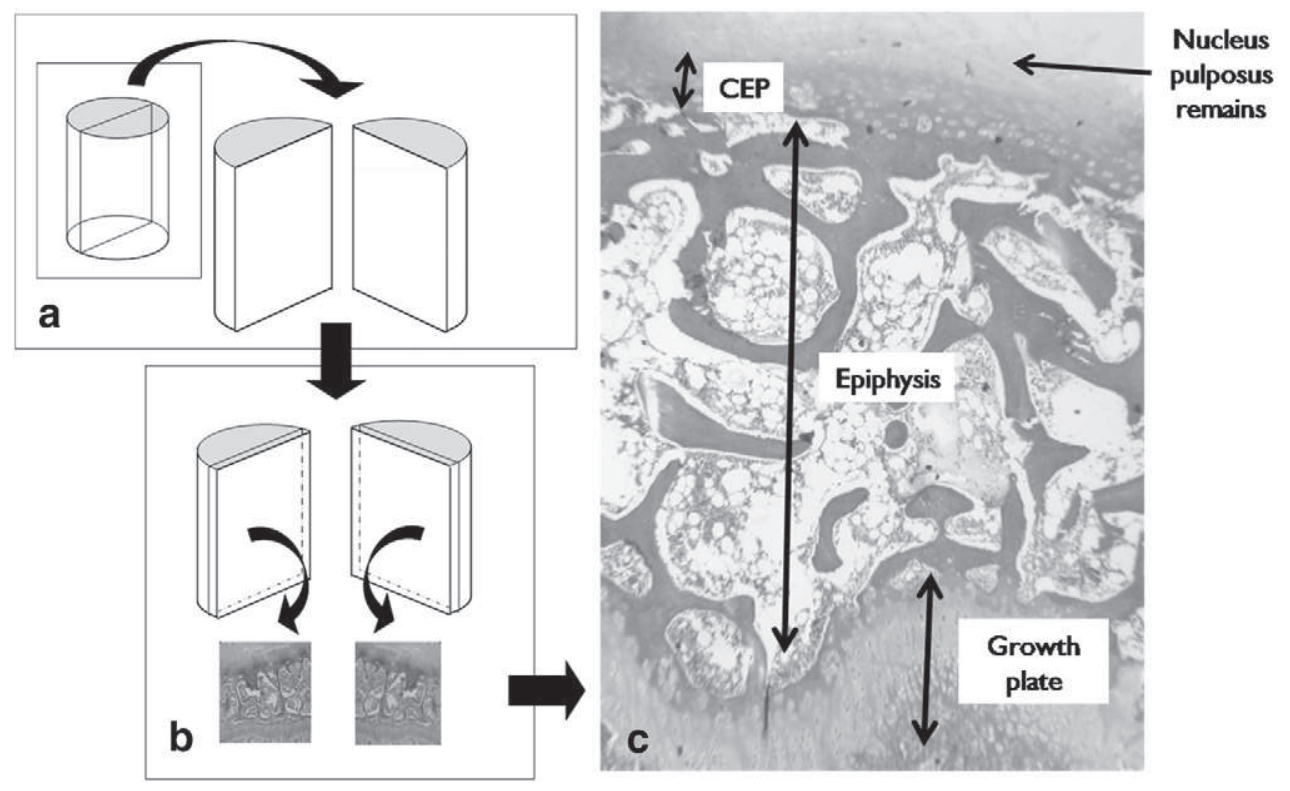

Fig. 2. Microscopic measurements. (a) - The specimen was first cut longitudinally to obtain 2 symmetrical hemicylinders. (b) - A histological section was taken from each hemicylinder. (c) - Two measurements of the thickness of the various layers (cartilage end plate, epiphysis and growth plate) were made using a microscope and a digital camera on each section.

$P<0.05$. Data were analyzed using Statview ${ }^{\circledR}$ software (SAS Institute Inc., USA).

\section{Results}

A preliminary statistical study (data not shown) demonstrated no significant differences between cranial and caudal end plates adjacent to the investigated IVD. Therefore, the data were pooled.

\subsection{Imaging}

The mean growth of $T_{1}-S_{1}$ spine segment ( $S$ : sacrum vertebra) was $10 \mathrm{~mm} / \mathrm{month}$. Final multiplanar CT scan demonstrated a substantial three-dimensional deformity in all six animals with an average of $42^{\circ}$ (21-55) right thoracic curve, $44^{\circ}\left(15-58^{\circ}\right)$ lordosis and $21^{\circ}(18-26)$ rotation (Fig. 3). Minor pull out or levering of the screws was noted in all of the specimens over the two month period though causing no implant failure or loosening. CT images and gross dissection showed no evidence of intervertebral fusion. No other complication was encountered and the animals remained healthy over the observation period.

\subsection{Effective permeability (Table 1)}

Effective permeability of the VEP was significantly different depending on the location $(P=0.002)$. It was greater in the center of the VEP than in its lateral zones. Average values were $1.56 \times 10^{-14} \mathrm{~m}^{4} / \mathrm{N} \mathrm{s}$ (SD 0.54) in the center, $1.16 \times 10^{-14} \mathrm{~m}^{4} / \mathrm{N} \mathrm{s}$ (SD 0.68) on the convex side $(-26 \%$, $P=0.01$ ), and $1.10 \times 10^{-14} \mathrm{~m}^{4} / \mathrm{N} \mathrm{s}$ (SD 0.45$)$ on the concave side ( $-29 \%$, $P=0.002)$. There was no statistical difference between the convex side and the concave side $(P=0.77)$.

Effective permeability of the VEP was significantly different depending on the vertebral level $(P=0.004)$. It was gradually decreased towards the apex of the deformity as shown in Fig. 4. It was significantly lower in A $\left(0.95 \times 10^{-14} \mathrm{~m}^{4} / \mathrm{N} \mathrm{s}\right.$, SD 0.45$)$ than in $A-1\left(1.25 \times 10^{-14} \mathrm{~m}^{4} / \mathrm{N} \mathrm{s}\right.$, $\mathrm{SD} 0.65, P=0.02), A+2\left(1.60 \times 10^{-14} \mathrm{~m}^{4} / \mathrm{N} \mathrm{s}, \mathrm{SD} 0.57, P=0.0006\right), A-2$ $\left(1.37 \times 10^{-14} \mathrm{~m}^{4} / \mathrm{N} \mathrm{s}, \mathrm{SD} 0.63, P=0.008\right), A+3\left(1.86 \times 10^{-14} \mathrm{~m}^{4} / \mathrm{N} \mathrm{s}\right.$, SD $0.30, P=0.0008)$ and $A-3\left(1.52 \times 10^{-14} \mathrm{~m}^{4} / \mathrm{N} \mathrm{s}, \mathrm{SD} 0.69, P=0.02\right)$.

There was no statistical difference in effective permeability of the VEP whether it was measured for flow in or flow out $(P>0.05)$.

\subsection{Microscopy}

The thickness of each constitutive layer of the VEP varied significantly depending on the localization $(P=0.0005)$. CEP was thinner in the center of the VEP $(9.6 \mu \mathrm{m}, \mathrm{SD} 3)$ than both in the convexity $(14 \mu \mathrm{m}, \mathrm{SD} 7.9, P=0.008)$ and the concavity $(15.2 \mu \mathrm{m}, \mathrm{SD}$ $6.7, P=0.0006)$. There was no significant difference either between convexity and concavity $(P=0.45)$. No calcification of the CEP was observed. Epiphysis was thinner in the center of the VEP $(60.7 \mu \mathrm{m}, \mathrm{SD}$ $37)$ than in the convexity $(116.5 \mu \mathrm{m}, \mathrm{SD} 40.2, P=0.0001)$ and the concavity $(119.3 \mu \mathrm{m}, \mathrm{SD} 43.7, P=0.0001)$. There was no significant difference either between convexity and concavity $(P=0.80)$. The growth plate was thinner in the center of the VEP $(12.2 \mu \mathrm{m}, \mathrm{SD} 5.4)$ than in the convexity $(26.4 \mu \mathrm{m}, \mathrm{SD} 14, P=0.003)$ and the concavity $(28 \mu \mathrm{m}, \mathrm{SD} 13.8, P=0.0004)$. There was no significant difference either between convexity and concavity $(P=0.59)$. All growth plates remained open without disruption.

The thickness of each constitutive layer of the VEP did not vary significantly depending on the vertebral level (CEP $P=0.60$, epiphysis $P=0.77$, growth plate $P=0.71$ and total VEP $P=0.71$ ) (Fig. 5).

None of the correlations between microscopic results and effective permeability of the VEP was statistically significant. The correlation coefficients were: $-0.24(-0.42,-0.04)$ with $P=0.22$ for the CEP, $-0.25(-0.43,-0.05)$ with $P=0.12$ for the epiphysis, -0.021 $(0.039,-0.01)$ with $P=0.24$ for the growth plate and $0.105(-0.236$, $0.424)$ with $P=0.55$ for the total VEP thickness.

\section{Discussion}

The influence of scoliosis on the permeability of the VEP has been investigated in human, as measured indirectly from nitrous oxide and then oxygen diffusion to the IVD (Bibby et al., 2002; Urban et al., 2001a, 2001b). It was found that permeability was severely reduced at the apex of a neuromuscular scoliosis (Urban et al., 2001a, 2001b). This was later confirmed when it was found that the apical IVD had the lowest oxygen and highest lactate concentrations (Bibby et al., 2002). Cell viability and glucose concentration were lower toward the convex side of the curve.

Remodeling of the VEP including calcifications of the CEP has been observed in scoliosis. It resulted in decreased permeability of the VEP, 
a

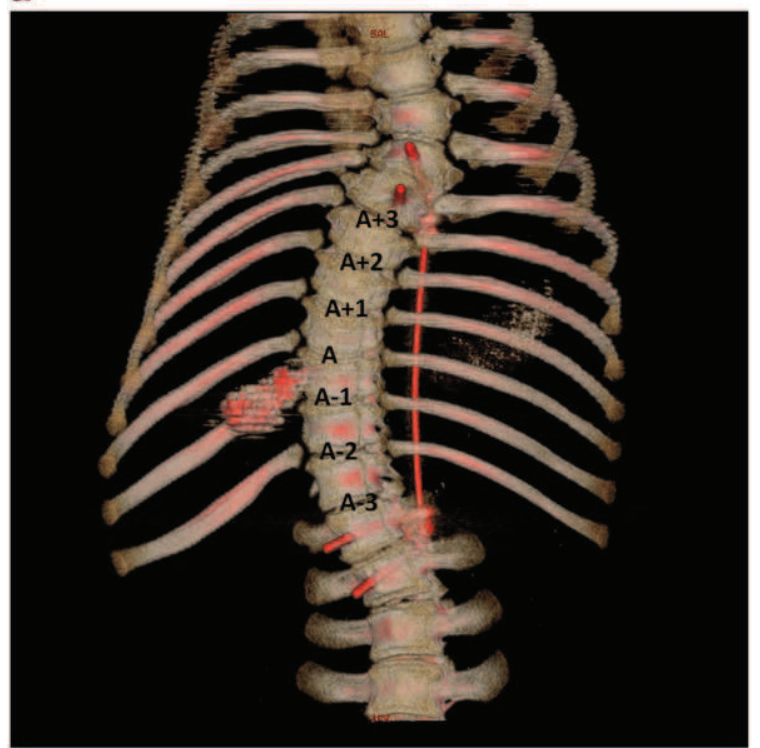

b

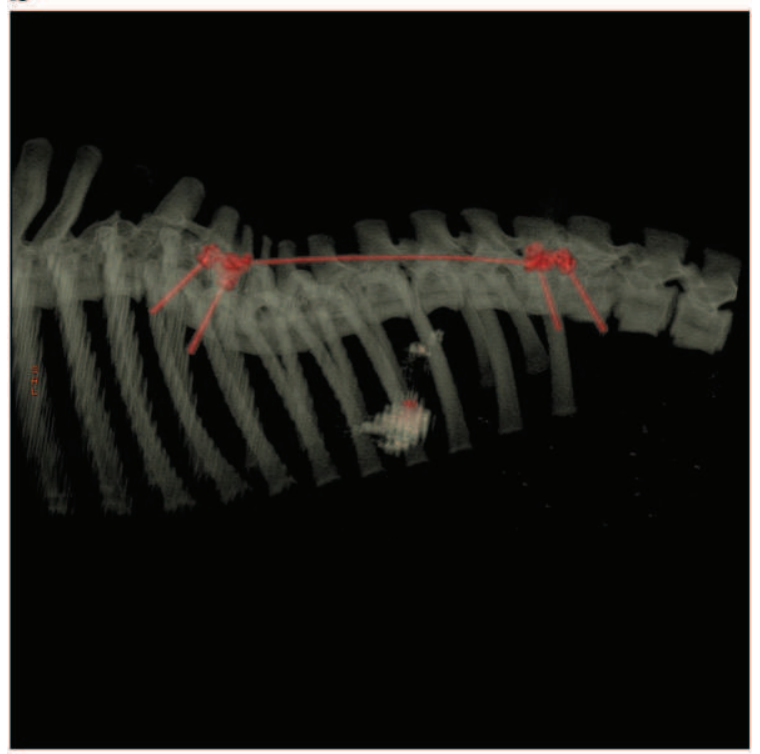

c

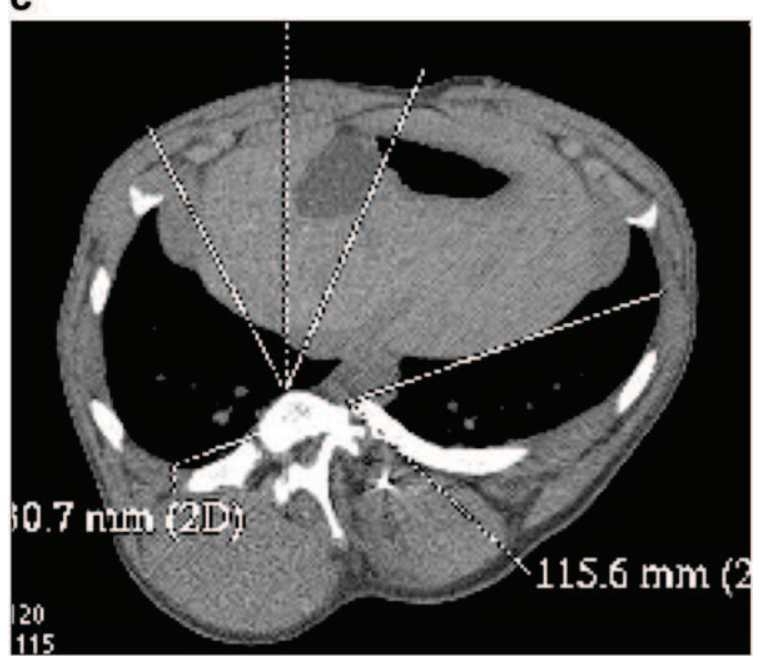

Fig. 3. Final CT scan demonstrating a scoliosis-like deformity (a) - Coronal reconstruction with a $42^{\circ}$ right thoracic curve. (b) - Sagittal reconstruction with a $38^{\circ}$ lordosis. (c) - Axial view with an $18^{\circ}$ vertebral rotation (T11).
Table 1

Mean effective permeability by vertebral level for flow in and flow out.

\begin{tabular}{llllll}
\hline \multirow{2}{*}{$\begin{array}{l}\text { Vertebral } \\
\text { level }\end{array}$} & Flow in & & \multicolumn{2}{l}{ Flow out } \\
\cline { 2 - 3 } \cline { 5 - 6 } & Mean & SD & & Mean & SD \\
\hline$A-3$ & 1.43 & 0.78 & 1.61 & 0.73 \\
$A-2$ & 1.29 & 0.94 & 1.40 & 0.89 \\
$A-1$ & 1.19 & 0.77 & 1.27 & 0.75 \\
Apex & 1.11 & 0.71 & 0.77 & 0.48 \\
$A+1$ & 1.27 & 0.83 & 1.11 & 0.79 \\
$A+2$ & 1.72 & 0.92 & 1.54 & 0.85 \\
$A+3$ & 1.81 & 0.82 & 1.80 & 0.58 \\
\hline
\end{tabular}

Values in $10^{-14} \mathrm{~m}^{4} / \mathrm{N} \mathrm{s}$. SD $=$ standard deviation.

changes in IVD composition and eventually disc degeneration (Antoniou et al., 2001; Haglund et al., 2009; Nachemson et al., 1970; Roberts et al., 1993, 1996; Urban et al., 2001a, 2001b). It remains unclear whether these changes were purely a consequence of the deformity and altered loading or whether they were participating in its generation or progression (Roberts et al., 1993).

Several attempts were made to create a spinal deformity in large animals using growth modulation and then to analyze its consequences at the IVD level. Braun et al. (2003) created an experimental structural scoliosis in an immature goat model by using 2 sublaminar hooks and a posterior rod. It is noteworthy that they had to add convex ribs resection and concave ribs tethering. Histology demonstrated concave trabecular and cortical thickening of the vertebral bodies, bone drift toward the concavity and thinning and disorganization of the growth plate. IVD analysis showed fibrosis and disorganization of the concave annulus fibrosus (AF). The nucleus pulposus (NP) was shifted toward the convexity. IVD composition was also affected with general decrease of hydroxyprolin content and decrease of prostaglandin in the nucleus pulposus suggestive of early degeneration.

Newton et al. applied an anterolateral flexible tether on the thoracic spine of rapidly growing calves by mean of two sets of screws and cables (Newton et al., 2008a, 2008b). Average $37.6^{\circ}$ coronal and $18^{\circ}$ sagittal deformity were obtained with vertebral wedging toward the tether. Disc thickness decreased significantly without wedging though water content was not different between control and tether groups. All vertebrae involved with the deformity in this study had been surgically exposed and instrumented.

Spinal growth modulation by tethering the anterolateral thoracic spine in mini pigs was more recently reported by Newton et al. (2008c). Average $15^{\circ}$ and $30^{\circ}$ coronal angulations were obtained respectively after six and twelve month observations as well as vertebral wedging. Disc wedging toward the tether was also observed with the NP shifted toward the tether in all specimens. IVDs and VEPs

Permeability
$\left(10^{-14} \mathrm{~m}^{4} / \mathrm{Ns}\right)$

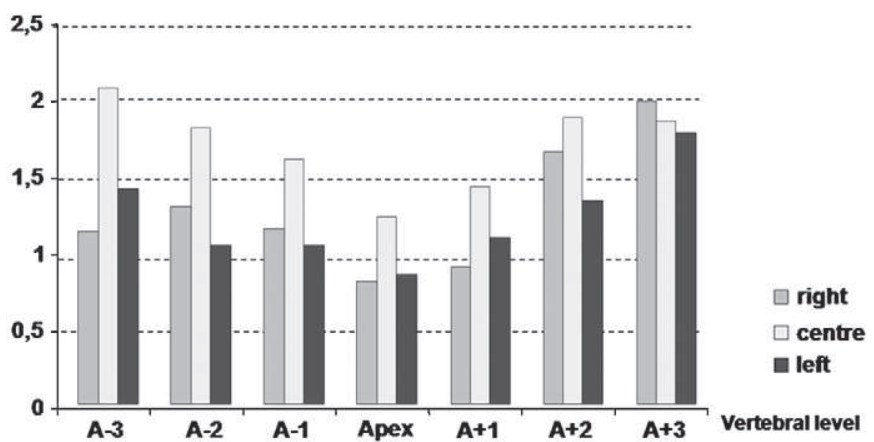

Fig. 4. Diagram showing the decreased effective permeability of the VEP towards the apex of the curve. Standard deviations were as follows: $A-3=0.69, A-2=0.63, A-1=0.65$, $A=0.45, A+1=0.55, A+2=0.57$, and $A+3=0.30$. Values in $10^{-14} \mathrm{~m}^{4} / \mathrm{N} \mathrm{s}$. 
a

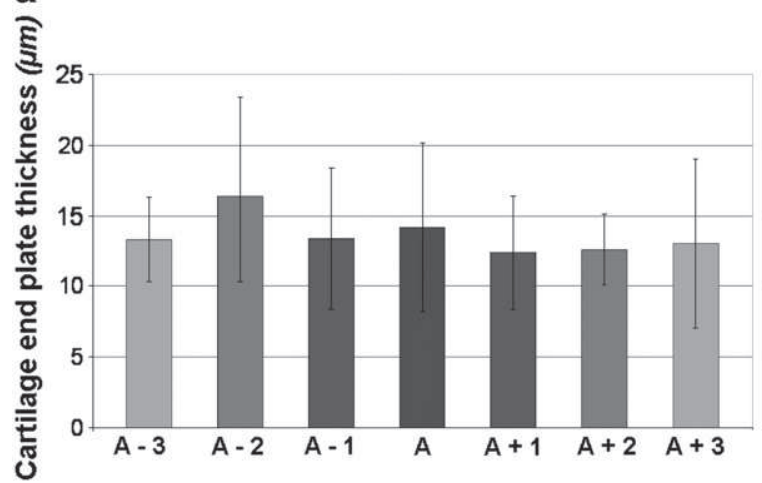

C

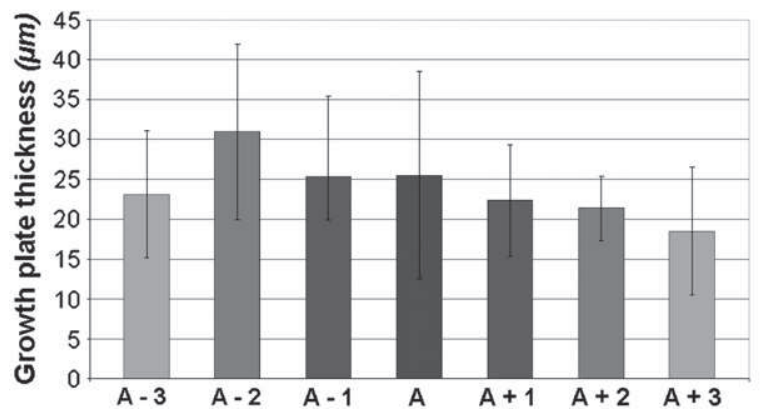

b
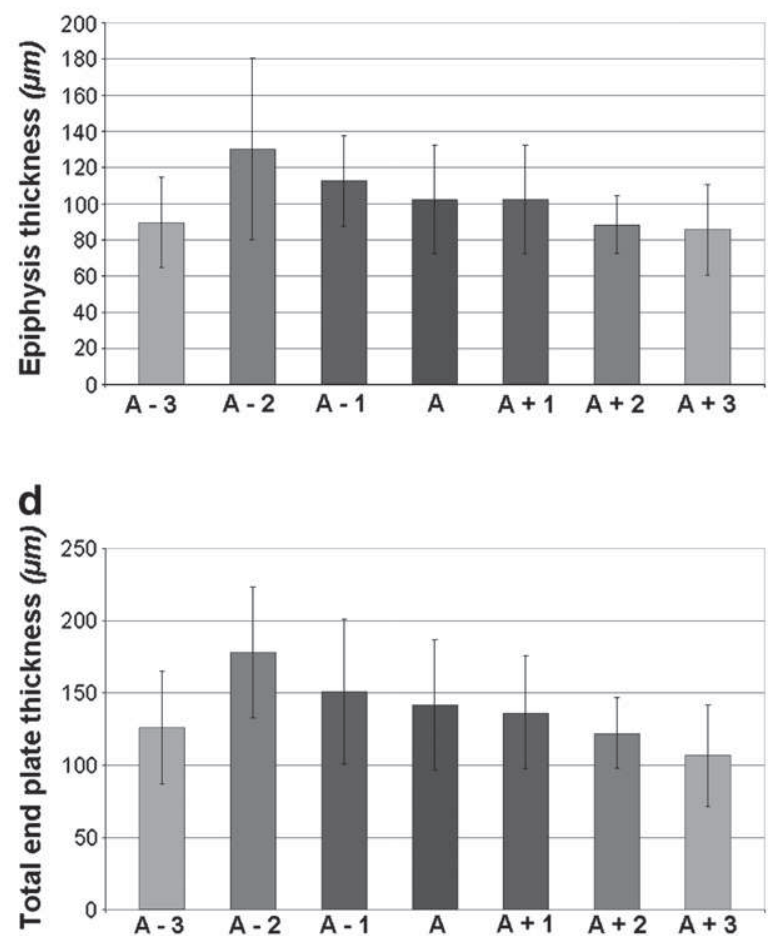

Fig. 5. Mean thickness of the different constitutive layers (bars) and standard deviations (plain lines) for each vertebral level in micrometers. (a) - Cartilage end plate. (b) Epiphysis. (c) Growth plate. (d) Total vertebral end plate.

were undamaged and showed no sign of degeneration on MRI. These authors hypothesized that the unexpected "reverse" disc wedging may represent a compensatory mechanism to maintain spinal alignment.

We could assume that the IVD has the ability to adapt to the spine loading up to a certain extent, depending on the growth rate, the vertebral level and the duration the strain is applied for. (Violas et al., 2007) reported on an MRI-based objective quantification of the volume and NP/AF ratio of lumbar IVDs below a posterior instrumentation for adolescent idiopathic scoliosis. IVD volume and NP/AF ratio were significantly increased after instrumentation as compared to preoperative values, highly suggesting a rehydration of the IVD after the proximal spine had been rebalanced and even loading restored.

Our study showed that a flexible left posterolateral tether created a progressive, structural lordoscoliotic curve convex to the right in the thoracic spine of an immature pig without violation of the spinal elements. Nonetheless, it provided a model to analyze the influence of a spine tether on the effective permeability of the VEP. Our results were consistent with data from the literature as the lowest value for effective permeability was measured at the apex of the curve (Bibby et al., 2002; Urban et al., 2001a, 2001b) and permeability was also greater in the center than in the periphery of the VEP (Maroudas et al., 1975; Roberts et al., 1997). No statistical difference was found between the convex side and the concave side. It appeared consistent that permeability of the whole VEP was decreased with little or no side variation.

In a previous study involving growing sheep without spine deformity, we found correlations between permeability and thickness of the VEP constitutive layers and highlighted the role of the fluid flow direction (Accadbled et al., 2008a, 2008b). However, we could not find in the present study such significant correlations. This could be related to the relatively small sample size and/or the animal studied (pig vs sheep). Variations of effective permeability might be related to the microarchitecture variations in the capillary network representing marrow contact channels through the VEP (Crock and Goldwasser, 1984; Kobayashi et al., 2008; Laffosse et al., 2010). Abnormal loading conditions may alter this capillary network in terms of porosity ratios and tortuosity given that these factors are of major influence on transport properties in porous media.

We acknowledge some limitations of the present study on a scoliosis porcine model. Firstly, the rapid vertebral growth of the animal model as compared to a human may overexaggerate spinal growth modulation. A quadruped is not submitted to the gravitational forces or distribution of body weight of a biped, therefore, growth modulation might have a different impact in humans. Secondly, the study lacked a control group without any instrumentation or only screws inserted (sham surgery) to compare the natural progression of spinal alignment and permeability in healthy animals. To reduce the number of sacrificed animal we decided to compare permeability between vertebral levels within the same tethered spine and we worked with six animals to improve statistics. In a preliminary study involving a porcine animal model showing a normal growth (Accadbled et al., 2008a), we designed the permeability measurement method and hence registered the first data for the permeability of the VEP. We didn't find any significant influence of the vertebral level (thoracic or lumbar).

Thirdly, the VEP in human is different from the VEP in other mammals such as pigs where there is a layer of trabecular bone or 'epiphysis' separating the CEP from the growth plate. In human, there is only a thin layer of dense bone located between the CEP and the growth plate. Even if the trabecular bone was remodeled under imbalanced loads (Laffosse et al., 2010), its contribution to the effective permeability was minimal because of its high porosity as compared to that of the CEP. Finally, our methodology could be considered as a relevant proposal to reproduce major mechanobiological events appearing in human scoliotic spine.

We generated a scoliosis-like three-dimensional deformity using a minimal invasive flexible tether. For the first time, to our knowledge, 
effective permeability of the VEP has been measured in an animal scoliosis model showing that growth modulation resulted in a decreased permeability of the VEP toward the apex of the curve. Of interest is the substantial residual spinal growth of our experimental model representing an opportunity for future deformity correction and mechanobiological parameter investigation.

\section{Acknowledgements}

Animal instrumentation was supported by Medtronic® Europe SA (Tolochenaz, Switzerland). The authors thank Dr E. Viguier and T. Cachon from the Department of Surgery, National Veterinary School of Lyon (France) for their assistance and expertise with the animal model.

\section{References}

Accadbled, F., Ambard, D., de Gauzy, J.S., Swider, P., 2008a. A measurement technique to evaluate the macroscopic permeability of the vertebral end-plate. Med. Eng. Phys. $30,116-122$.

Accadbled, F., Laffosse, J.M., Ambard, D., Gomez-Brouchet, A., de Gauzy, J.S., Swider, P. 2008b. Influence of location, fluid flow direction, and tissue maturity on the macroscopic permeability of vertebral end plates. Spine 33, 612-619.

Antoniou, J., Arlet, V., Goswami, T., Aebi, M., Alini, M., 2001. Elevated synthetic activity in the convex side of scoliotic intervertebral discs and endplates compared with normal tissues. Spine 26, E198-E1206.

Betz, R.R., Kim, J., D'Andrea, L.P., Mulcahey, M.J., Balsara, R.K., Clements, D.H., 2003. An innovative technique of vertebral body stapling for the treatment of patients with adolescent idiopathic scoliosis: a feasibility, safety, and utility study. Spine (Phila Pa 1976) 28, S255-S265.

Bibby, S.R., Fairbank, J.C., Urban, M.R., Urban, J.P., 2002. Cell viability in scoliotic discs in relation to disc deformity and nutrient levels. Spine 27, 2220-2228 (discussion 2227-2228).

Biot, M.A. 1941. J. Appl. Phys. 12, 155-164.

Braun, J., Ogilvie, J., Akyuz, E., Brodke, D., Bachus, K., Stefko, R., 2003. Experimental scoliosis in an immature goat model: a method that creates idiopathic-type deformity with minimal violation of the spinal elements along the curve. Spine 28 , 2198-2203.

Braun, J.T., Ogilvie, J.W., Akyuz, E., Brodke, D.S., Bachus, K.N., 2006. Creation of an experimental idiopathic-type scoliosis in an immature goat model using a flexible posterior asymmetric tether. Spine 31, 1410-1414.

Brodin, H., 1955. Path of nutrition in articular cartilage and the intervertebral disk. Acta Orthop. Scand. 24, 177-183.

Crock, H.V., Goldwasser, M., 1984. Anatomic studies of the circulation in the region of the vertebral end-plate in adult Greyhound dogs. Spine 9, 702-706.

Donisch, E., Trapp, W., 1971. The cartilage endplates of the human vertebral column (some considerations of postnatal development). Anat. Rec. 169, 705-716.

Dullien, F.A.L., 1992. Porous media, fluid transport and pore structure. Academic Press Inc, USA.
Haglund, L., Ouellet J., Roughley, P., 2009. Variation in chondroadherin abundance and fragmentation in the human scoliotic disc. Spine (Phila Pa 1976) 34, 1513-1518.

Kobayashi, S., Baba, H., Takeno, K., Miyazaki, T., Uchida, K., Kokubo, Y., 2008. Fine structure of cartilage canal and vascular buds in the rabbit vertebral endplate. Laboratory investigation. J. Neurosurg. Spine 9, 96-103.

Laffosse, J.M., Accadbled, F., Bonnevialle, N., Gomez-Brouchet, A., de Gauzy, J.S., Swider, P., 2010. Remodelling of vertebral endplate subchondral bone in scoliosis: a micro-CT analysis in a porcine model. Clin. Biomech. 25, 636-641.

Maroudas, A., Stockwell, R.A., Nachemson, A., Urban, J., 1975. Factors involved in the nutrition of the human lumbar intervertebral disc: cellularity and diffusion of glucose in vitro. J. Anat. 120, 113-130.

Nachemson, A., Lewin, T., Maroudas, A., Freeman, M.A., 1970. In vitro diffusion of dye through the end-plates and the annulus fibrosus of human lumbar inter-vertebral discs. Acta Orthop. Scand. 41, 589-607.

Newton, P.O. Fricka, K.B., Lee, S.S., Farnsworth C. Cox, T.G Mahar, A.T., 2002. Asymmetrical flexible tethering of spine growth in an immature bovine model. Spine 27, 689-693

Newton, P.O., Farnsworth, C.L., Faro, F.D., Mahar, A.T., Odell, T.R., Mohamad, F., 2008a. Spinal growth modulation with an anterolateral flexible tether in an immature bovine model: disc health and motion preservation. Spine 33, 724-733.

Newton, P.O., Upasani, V.V., Farnsworth, C.L., Oka, R., Chambers, R.C., Dwek, J., 2008b. Spinal growth modulation with use of a tether in an immature porcine model. J. Bone Joint Surg. Am. 90, 2695-2706.

Odent, T. Cachon, T. Peultier, B. Gournay, J. Jolivet, E, Viguier, E., 2008. Porcine scoliosis model based on animal growth created with minimal invasive off-set tethering. 43rd Annual Meeting Scoliosis Research Society, Salt Lake City, Utah, USA.

Pomero, V., Mitton, D., Laporte, S., de Guise, J.A., Skalli, W., 2004. Fast accurate stereoradiographic 3D-reconstruction of the spine using a combined geometric and statistic model. Clin. Biomech. 19, 240-247.

Roberts, S., Menage, J., Urban, J.P., 1989. Biochemical and structural properties of the cartilage end-plate and its relation to the intervertebral disc. Spine 14, 166-174.

Roberts, S., Menage, J., Eisenstein, S.M., 1993. The cartilage end-plate and intervertebral disc in scoliosis: calcification and other sequelae. J. Orthop. Res. 11, 747-757.

Roberts, S., Urban, J.P., Evans, H., Eisenstein, S.M., 1996. Transport properties of the human cartilage endplate in relation to its composition and calcification. Spine 21, 415-420.

Roberts, S., McCall, I.W., Menage, J., Haddaway, M.J., Eisenstein, S.M., 1997. Does the thickness of the vertebral subchondral bone reflect the composition of the intervertebral disc? Eur. Spine J. 6, 385-389.

Selard, E., Shirazi-Adl, A., Urban, J., 2003. Finite element study of nutrient diffusion in the human intervertebral disc. Spine 28, 1945-1953.

Taylor, T.K. Ghosh, P., Braund, K.G., Sutherland, J.M., Sherwood, A.A. 1976. The effect of spinal fusion on intervertebral disc composition: an experimental study. J. Surg. Res. 21, 91-104.

Urban, M.R., Fairbank, J.C., Bibby, S.R., Urban, J.P., 2001a. Intervertebral disc composition in neuromuscular scoliosis: changes in cell density and glycosaminoglycan concentration at the curve apex. Spine 26, 610-617.

Urban, M.R., Fairbank, J.C., Etherington, P.J., Loh, F.L., Winlove, C.P., Urban, J.P., 2001b. Electrochemical measurement of transport into scoliotic intervertebral discs in vivo using nitrous oxide as a tracer. Spine 26, 984-990.

Violas, P., Estivalezes, E., Briot, J., Sales de Gauzy, J., Swider, P., 2007. Quantification of intervertebral disc volume properties below spine fusion, using magnetic resonance imaging, in adolescent idiopathic scoliosis surgery. Spine 32, E405-E412. 